COGNITIVE

NEUROSCIENCE

\section{Increasing corvid tolerance to humans in urban ecosystems with increasing latitude}

\section{Nadezhda Poddubnaya, Tatyana Korotkova, and Polina Vanicheva}

Department of Biology, Cherepovets State University, 5 Lunacharsky Ave., Cherepovets, Vologda Region, 162600, Russian Federation

Address correspondence and requests for materials to Nadezhda Poddubnaya, poddoubnaia@mail.ru

\begin{abstract}
The rapid growth of cities causes behaviour changes in birds in response to urban environmental factors. The avian response to human disturbance has recently been studied by a non-invasive research tool as an alert distance (AD) and a flight initiation distance (FID) assessment. The tolerance of hooded crows $(n=395)$, jackdaws $(n=394)$ and rooks $(n=169)$ to humans was assessed by AD and FID. It was shown that the FID of all species is maximal during the summer, when the parents send clear "danger - fly away" signals to the young and the birds fly away. The AD and FID of the three species reliably correlates with the season. Rooks showed FID species-specificity in seven cities of Eastern Europe. Comparison of the attitude of birds to people in cities that have similarities in human culture showed that tolerance increases with increasing latitude in all species and is statistically significant only in the jackdaw. This should be taken into account in environmental protection measures.
\end{abstract}

Keywords: animal behaviour, alert distance, flight initiation distance, Corvus cornix, Corvus monedula, Corvus frugilegus.

\section{Introduction}

Currently, up to $55 \%$ of the world's human population lives in cities (Demographia, 2018) - a new environment for wild species. Solutions to new environmental challenges depend primarily on the objective knowledge of the processes in urban ecosystems. The most significant processes relate to adaptation to new parameters within the urban environment, especially animal responses to external influences. Birds are an ecologically flexible group of vertebrates which can extend their distribution into human settlements (Clergeau et al., 1998; Luniak, 2004; Jokimäki et al., 2012; Zimaroyeva et al., 2016; Matsyura et al., 2015a; Isaksson, 2018). Their behaviour changes in response to urban environmental factors such as air pollution, artificial light at night, noise, different kinds of food, and different predation pressures (Ydenberg and Dill, 1986; Tarlow and Blumstein, 2007; Møller et al., 2015; Piratelli et al., 2015; Isaksson, 2018). The main contributing factors are related to human presence (human disturbances). Animals will either leave the city or decrease their fear and increase their tolerance towards humans.

The avian response to human disturbance has recently been studied using a non-invasive research tool known as a flight initiation distance (FID) assessment (e.g., Ydenberg and Dill, 1986; Fernández-Juricic et al., 2005; Rezanov, 2007; Weston et al., 2012; Bateman and Fleming, 2015; Cooper and Blumstein, 2015; Samia et al., 2015a; Blumstein et al., 2016; Blumstein, 2019), also known as "scare away distance" in Russia (Vladyshevsky, 1984). The use of FID has shown that escape probability and flight range increase with an increase in the risk of predation and decrease with an increased cost of escape (Cooper et al., 2015; Møller et al., 2015; Samia et al., 2017). Evacuation distance can vary significantly depending on many variables: body size (Laursen et al., 2005; Bregnballe et al., 2009; Samia et al., 2017), bird age, 
season, observer clothing colour and observer behaviour, and flock size and composition (e.g., Bregnballe et al., 2009; Matsyura et al., 2015a, b). Several recent studies have documented geographic variation of FID (Schemske et al., 2009; Díaz et al., 2013; Blumstein et al., 2016; Møller et al., 2016). FID is well studied for many parts of the world including North America (e.g., Blumstein, 2006; Clucas and Marzluff, 2012; Livezey et al., 2016), Australia (Blumstein, 2006), South America (Fernández-Juricic et al., 2005; Piratelli et al., 2015), and Western Europe (e.g., Blumstein, 2006; Clucas and Marzluff, 2012; Legagneux and Ducatez, 2013), but it is poorly studied in Eastern Europe. The database of bird FIDs includes 650 species from the USA (Livezey et al., 2016), 250 species from Australia (Weston et al., 2012) and approximately 10 in Eastern Europe (Aparova, 2003; Rezanov, 2007, 2018; Vorontsova, 2009; Matsyura et al., 2015a, b; Zimaroyeva et al., 2016). Comparative studies of human and bird behaviour in two urban areas (Seattle, Washington, USA and Berlin, Germany) on two different continents found that human cultural differences influence bird behaviour (Clucas and Marzluff, 2012). In Eastern Europe, several species of corvid have been studied in cities that have similarities in urban cover, population density, and relationships, as well as similarities in human culture, socio-economic conditions and education. These cities are located at different latitudes. We assessed hooded crow Corvus cornix, jackdaw Corvus monedula, and rook Corvus frugilegus tolerance to people in Cherepovets, Russia, which is located farther north than other locations of corvid studies, to investigate trends in tolerance along a latitudinal gradient.

\section{Material and Methods}

All bird observations were conducted in 2017-2018 within the city of Cherepovets $\left(59^{\circ} 07^{\prime} \mathrm{N}, 37^{\circ} 53^{\prime} \mathrm{E}\right.$, area of $121 \mathrm{~km}^{2}, 135 \mathrm{~m}$ a.s.l., estimated population 318,500 (Cherepovets, 2003), located in the central part of the East European Plain (Vologda region, Upper Volga). The human residential quarters in the city are separated by traditional habitats of Corvidae - tree clusters, shrubs, lawns, meadows and cottage areas.

To assess the tolerance of birds by their reaction to the stimulus, the following indicators were used: alert distance $(\mathrm{AD})$, the distance between the observer and the animal when it changes its behaviour in response to the approaching observer (Fernández-Juricic et al., 2005; Bateman and Fleming, 2015; Cooper and Blumstein, 2015) and flight initiation distance (FID), the distance between the observer and the animal when it flies and moves away from the observer (e.g., Fernández-Juricic et al., 2005; Blumstein, 2005, 2006).

We followed the standard protocol that is widely used in previous studies (Fernández-Juricic et al., 2005; Blumstein, 2005, 2006; Møller, 2008; Bateman and Flem- ing, 2015; Cooper and Blumstein, 2015). Observations were done between 08.00 and 18.00 each day. After locating a bird using binoculars, individual observers approached the animals at a steady pace ( $1 \mathrm{step} / \mathrm{s}, 0.5 \mathrm{~m} / \mathrm{s}$ ) at a linear trajectory, in areas without shrubs or trees visually blocking the pathway. The observer measured $\mathrm{AD}$ and FID following Fernández-Juricic and Schroeder (2003) and Blumshtine (2005, 2006). A modified protocol from Rezanov (2002) was followed to study other components of escape behaviour including jump-off or walking away from the observer. We named the two components of the FID index FID-F and FID-MG; if the bird flew, it was categorised as FID-F and if it moved away from the observer on the ground, it was categorised as FID-MG. We determined the AD, FID-F and FID-MG for only adult birds in spring and summer and for both adults and older chicks from late summer on because the older chicks are indistinguishable from adults at this time. We determined the seasonal differentiation as follows: winter (November 1 - February 28; local and predominantly non-local birds), spring (March $1-$ June 30; nesting and post-nesting periods; local birds), summer (July 1 - August 31; post-nesting periods; local and non-local birds) and autumn (September 1 - October 30; local and non-local birds). A total of $958 \mathrm{AD}$ and 958 FID were measured for rooks $(n=169)$, hooded crows $(n=395)$, and Eurasian jackdaws $(n=394)$.

Statistical data processing was performed with the Statistica-10 software. The impact of season on the measured parameters was investigated with the KruskalWallis ANOVA and Median test $(p<0.05)$.

\section{Results}

Samia et al. (2017) showed that in addition to the FID, it is necessary to study other components of escape behaviour that can provide a complementary perspective to the study of antipredator responses. Our study of flight, jump-off, or walking away from an observer (Rezanov, 2018) indicated that the main form of risk-avoiding behaviour of Corvidae is flight (Table 1, Fig. 1). Only the flight response was selected by the three species in summer, when parents accompany chicks in their first months of life. The flight of parents sends a clear "danger - fly away" signal to the young and the birds fly away. In other seasons, birds used both flight and movement

Table 1. Avoiding behaviour - movement on the ground in different seasons of the year (FID-MG) (\%)

\begin{tabular}{l|c|c|c|c}
\hline \multicolumn{1}{c|}{ Species } & Spring & Summer & Autumn & Winter \\
\hline Hooded crow & 0 & 0 & 32 & 20 \\
\hline Rook & 8 & 0 & 10 & - \\
\hline Eurasian jackdaw & 4 & 0 & 20 & 12 \\
\hline
\end{tabular}




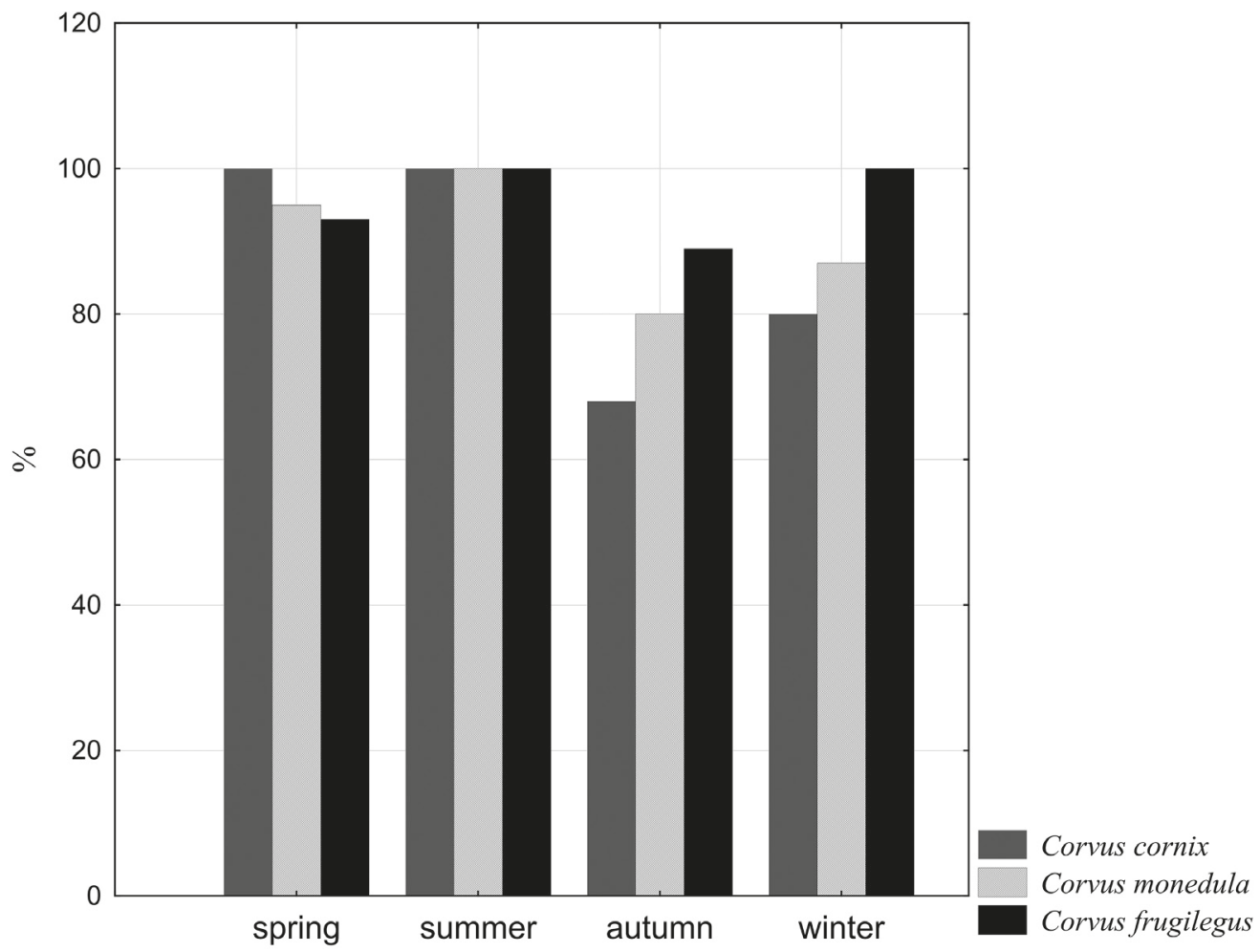

Fig. 1. Flight response in different seasons of the year (FID-F; \% of samples avoiding behaviour) of Corvus cornix (spring $n=82$, summer $n=60$, autumn $n=82$, winter $n=164$ ), of Corvus monedula (spring $n=110$, summer $n=94$, autumn $n=106$, winter $n=4$ ), and of Corvus frugilegus (spring $n=116$, summer $n=23$, autumn $n=24$, winter $n=6$ ).

on the ground. In autumn and winter, the index of riskavoiding behaviour (flight or move away) decreased. This is apparently due to the reaction of young birds which, according to Weston et al. (2012) and our observations, allow observers to approach closer to them than adult birds. The frequency of FID-MG of adult rooks and jackdaws was $8 \%$ and $4 \%$ in spring, respectively. Judging by the fact that this indicator coincides with the percentage of non-breeding rook individuals, perhaps, it is they who behave in this way. In autumn, the frequency of FID-MG was one-third of FID for hooded crows, one-fifth for jackdaws and only one-tenth for rooks. In winter, the frequency of FID-MG decreased to one-fifth of FID for hooded crows and one-eight for jackdaws.

All species showed alertness in all cases when the source of danger approached, and the frequencies of alertness and flight plus moving away from the observer for the three species was approximately the same: hooded crow, $53 \%$ and $47 \%$; rook, $55 \%$ and $45 \%$; and jackdaw, $52 \%$ and $48 \%$.

The annual average flight and move away was $84 \%$ for hooded crows, $94 \%$ for rooks, and $90 \%$ for jackdaws. In the reproductive period, especially in the summer when parents accompany young chicks, the flight of adult birds was observed in almost all patterns (Fig. 1).
In the autumn to winter periods, hooded crows were less wary than jackdaws and rooks (Fig. 1).

The AD and FID of hooded crows varied from $0 \mathrm{~m}$ to $11 \mathrm{~m}$. The variation (CV) of FID was $65 \%$ and the variation of $\mathrm{AD}$ was slightly lower at $57 \%$. Both types of reactions had a maximum coefficient of variation in winter and a minimum in summer. The average seasonal $\mathrm{AD}$ and FID were maximum in spring $(4.26 \pm 0.22$ and $3.40 \pm 0.21 \mathrm{~m}$, respectively), decreased in summer $(2.77 \pm$ 0.15 and $2.34 \pm 0.13 \mathrm{~m})$, were minimal in autumn in September-October $(2.23 \pm 0.15$ and $1.79 \pm 0.12 \mathrm{~m})$ and varied little from autumn to winter (in November-February; $2.83 \pm 0.23$ and $2.26 \pm 0.20 \mathrm{~m}$; Fig. $2 \mathrm{a}$ ). The $\mathrm{AD}$ and FID depended reliably on the season (Kruskal-Wallis test: $\alpha=0.05, \mathrm{H}=6.0091, p=0.01242$ ).

The birds reacted with more wariness to humans during nesting and post-nesting periods (Fig. 1). Most individuals of the population had similar reactions, and only a few individuals showed different responses ( $\mathrm{min}$ $0 \mathrm{~m}$, max $11 \mathrm{~m}$; Fig. 2a). Maximum distances were observed in winter, when non-native individuals dominate in the hooded crow population (Korotkova and Poddubnaya, 2019).

The AD and FID of rooks varied from $2 \mathrm{~m}$ to $12 \mathrm{~m}$ and from $1 \mathrm{~m}$ to $12 \mathrm{~m}$, respectively. The variation (CV) 

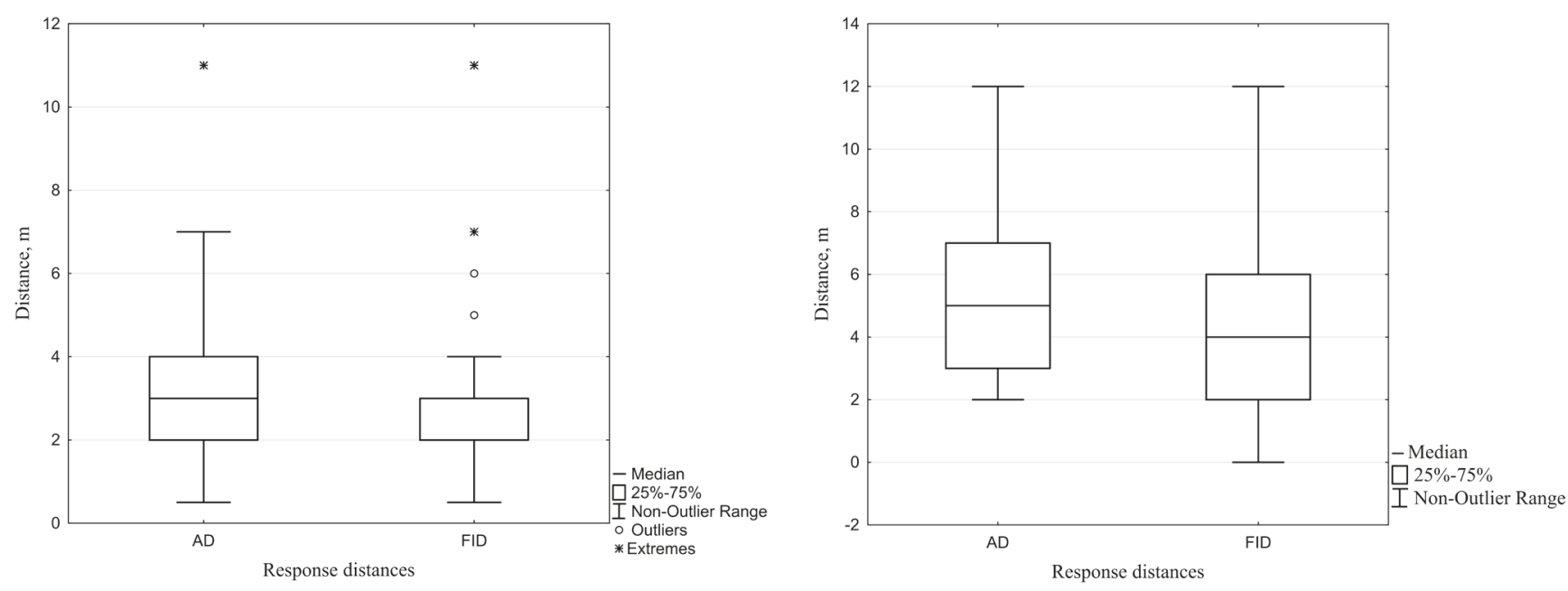

Fig. 2. Response distances of alert - AD and flight - FID: Corvus cornix (a), Corvus frugilegus (b), Corvus monedula (c).

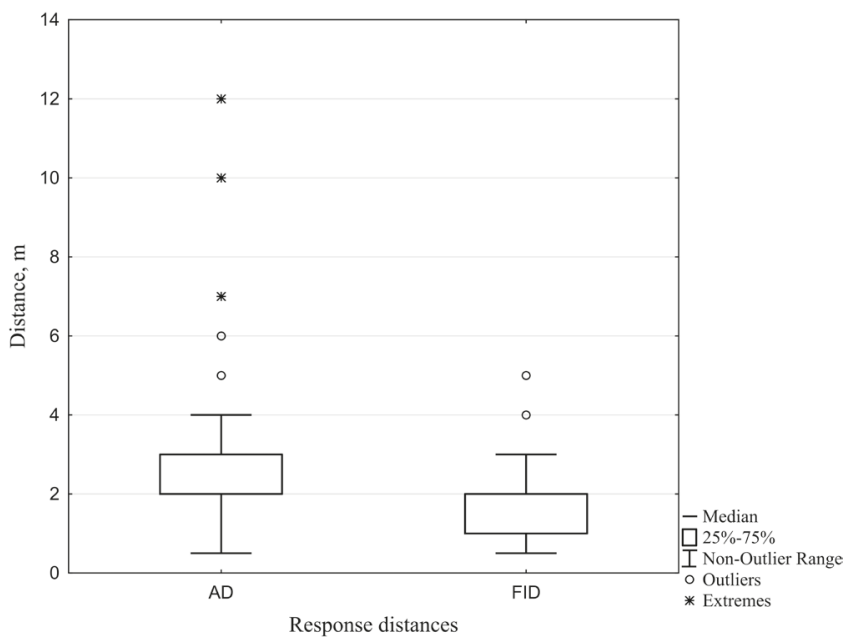

of $\mathrm{AD}$ was $52 \%$, and the variation of FID was $62 \%$. Both types of reactions had a maximum coefficient of variation in summer, when the population consists of local non-breeding adults (about $10 \%$ of the population of adult birds), parents with chicks, and non-local birds, i.e., when there is the greatest variety of demographic structure. Both types of reactions had a minimum coefficient of variation in autumn.

The average seasonal $\mathrm{AD}$ and FID of rooks were maximum in spring $(6.06 \pm 0.40$ and $4.91 \pm 0.35 \mathrm{~m}$, respectively), decreased in summer (4.5 \pm 0.76 and $4.30 \pm$ $0.89 \mathrm{~m})$, and were minimal in autumn $(3.09 \pm 0.21$ and $2.62 \pm 0.18 \mathrm{~m}$; Fig. $2 \mathrm{~b}$ ). The annual average FID was $4.6 \mathrm{~m}$, which is higher than that of hooded crows and jackdaws (Kruskal-Wallis test: $\alpha=0.05, \mathrm{H}=90.25908, p=0.0000$ ). The AD and FID of rooks depended reliably on the season (Kruskal-Wallis test: $\alpha=0.05, \mathrm{H}=5.4987, p=0.0190$ ).

The AD and FID of jackdaws varied from $0.5 \mathrm{~m}$ to $12 \mathrm{~m}$ and from $1 \mathrm{~m}$ to $5 \mathrm{~m}$, respectively (Fig. $2 \mathrm{c}$ ). The variation $(\mathrm{CV})$ of $\mathrm{AD}$ was $58 \%$, and the variation of FID was $47 \%$. Both types of reactions had a maximum coefficient of variation in autumn and a minimum in winter.

The average seasonal AD of jackdaws was maximum in summer $(3.10 \pm 0.22 \mathrm{~m})$, and was minimum in the winter - spring period $(2.48 \pm 0.16 \mathrm{~m}$ and $2.25 \pm$ $0.15 \mathrm{~m})$. The average seasonal FID was maximum in summer $(2.29 \pm 0.11 \mathrm{~m})$ and minimum in winter $(1.60 \pm$ $0.10 \mathrm{~m}$ ), increasing slightly in spring. The AD and FID of jackdaws depends reliably on the season (Kruskal-Wallis test: $\alpha=0.05, \mathrm{H}=1.58435, p=0.00007)$.

Comparison of the tolerance of three species of corvids to humans in the urban ecosystem of Cherepovets showed escape behaviours. The FID-F values were (in descending order): rook ( $94 \%$ of cases), Eurasian jackdaw (90\%), and hooded crow (84\%; Fig.1). We ranked the species according to their annual average $\mathrm{AD}$ (in descending order): rook (5.45 $\pm 0.32 \mathrm{~m})$, hooded crow $(2.92 \pm 0.12 \mathrm{~m})$, and Eurasian jackdaw $(2.64 \pm 0.11 \mathrm{~m})$. The annual average FID-F values were (in descending order): $\operatorname{rook}(4.57 \pm 0.29 \mathrm{~m})$, hooded crow $(2.45 \pm 0.11 \mathrm{~m})$, and Eurasian jackdaw (1.94 $\pm 0.06 \mathrm{~m}$; Table 2). The jackdaws took off more often than the hooded crows $(90 \%$ and $84 \%)$, but from a smaller distance $(1.94 \pm 0.06 \mathrm{~m}$ and $2.45 \pm 0.11 \mathrm{~m})$. 
Table 2. The annual average FID of three species of corvids in Eastern Europe

\begin{tabular}{|c|c|c|c|c|}
\hline City, coordinates & Hooded crow & Rook & Eurasian jackdaw & Reference \\
\hline $\begin{array}{l}\text { Cherepovets } \\
59^{\circ} 07^{\prime} \mathrm{N} 37^{\circ} 53^{\prime} \mathrm{E}\end{array}$ & $\begin{array}{c}2.45 \pm 0.11 \\
(n=395)\end{array}$ & $\begin{array}{c}4.57 \pm 0.29 \\
(n=169)\end{array}$ & $\begin{array}{c}1.94 \pm 0.06 \\
(n=394)\end{array}$ & Our data \\
\hline $\begin{array}{l}\text { Pskov } \\
57^{\circ} 49^{\prime} \text { N } 28^{\circ} 20^{\prime} \text { E }\end{array}$ & $\begin{array}{c}4.22 \\
(n=87)\end{array}$ & $\begin{array}{c}5.23 \\
(n=83)\end{array}$ & $\begin{array}{c}3.18 \\
(n=307)\end{array}$ & Vorontsova, 2009 \\
\hline $\begin{array}{l}\text { Ivanovskiy Region } \\
56^{\circ} 59^{\prime} \mathrm{N} 40^{\circ} 58^{\prime} \mathrm{E}\end{array}$ & - & $5.39 \pm 0.92$ & $4.04 \pm 0.35$ & Ryabov, 2002 \\
\hline \multirow{2}{*}{$\begin{array}{l}\text { Moscow } \\
55^{\circ} 45^{\prime} N 37^{\circ} 37^{\prime} \mathrm{E}\end{array}$} & $2.51(n=323)$ & - & - & Rezanov, 2007 \\
\hline & - & - & $3.31(n=117)$ & Rezanov, 2018 \\
\hline $\begin{array}{l}\text { Saransk } \\
54^{\circ} 11^{\prime} \mathrm{N} 45^{\circ} 11^{\prime} \mathrm{E}\end{array}$ & - & - & 3.71 & Kelin, Spiridonov, 2009 \\
\hline $\begin{array}{l}\text { Orenburg } \\
51^{\circ} 46^{\prime} N 55^{\circ} 06^{\prime} \mathrm{E}\end{array}$ & $\begin{array}{c}12.5 \\
(n=10)\end{array}$ & $\begin{array}{c}6.7 \\
(n=10)\end{array}$ & $\begin{array}{c}13.2 \\
(n=10)\end{array}$ & Fisun, 2007 \\
\hline $\begin{array}{l}\text { Zhytomyr } \\
50^{\circ} 15^{\prime} \mathrm{N} 28^{\circ} 39^{\prime} \mathrm{E}\end{array}$ & $\begin{array}{l}5.5 \pm 0.3 \\
(n=153)\end{array}$ & $\begin{array}{l}5.2 \pm 0.2 \\
(n=341)\end{array}$ & $\begin{array}{l}4.9 \pm 0.2 \\
(n=190)\end{array}$ & $\begin{array}{l}\text { Matsyura, Jankowski, } \\
\text { Zimaroyeva, 2015a,b }\end{array}$ \\
\hline
\end{tabular}

In Cherepovets, indicators of hooded crow tolerance towards humans were still variable. Between the $\mathrm{AD}$ and the flight distance of hooded crows, there was no significant connection (Spearman correlation, $r=$ $0.12, p=0.15$ ), while for rooks, there was a reliable strong direct connection $(r=0.89, p=0.000)$ and for jackdaws, a moderate direct connection $(r=0.38, p=$ 0.000). Comparison of the attitude of birds to people in cities that have similarities in human culture and socioeconomic conditions and education showed that in higher latitudes, the tolerance increases (FID decreases) in all species (Table 2), and is statistically significant only in the jackdaw (Spearman correlation $r=-0.8719, p=$ $0.041563)$.

\section{Discussion}

Studies have demonstrated that tolerance/FID can be influenced by many variables: habitat type, number of birds in a group, direction and parameters of observer approach, season (e.g. Weston et al., 2012; Matzyura et al., 2015a, b), starting distance of observer (Matzyura et al., 2015a), life-history characteristics (Weston et al., 2012; Møller and Garamszegi, 2012), and bird age (e.g. Glover et al., 2011). Birds are most cautious in the period of brooding and feeding of chicks (Rezanov, 2007; Weston et. al., 2012; Blumstein et al., 2016) and their accompaniment in summer, when flight is the only escape behaviour. The other components of escape behaviour (jump-off or walking away from an observer) may be associated with young independent individuals who are less careful than adults (Weston et al., 2012). FID-MG frequency reduction in winter occurs appar- ently because there is a large proportion of non-resident rural birds, which according Møller et al. (2013), Matzyura et al. (2015b) and Samia et al. (2017) are more cautious than their city-dwelling counterparts (Møller et al., 2013; Matzyura et al., 2015a; Samia et al., 2017). This most likely explains the data obtained in the present study and by Rezanov (2007) and Matzyura et al. (2015a,b), which indicate that the maximum variation of $\mathrm{AD}$ and FID-F of hooded crows and jackdaws occurs in autumn and winter and the minimum in spring and summer. The maximum variation of $\mathrm{AD}$ and FID-F of migratory rooks in Cherepovets was observed in summer, when its population had the greatest demographic diversity. The fact that $\mathrm{AD}$ and FID largely depend on the demographic structure has been noted by many researchers (Rezanov, 2007; Tarlow and Blumstein, 2007; Cooper and Blumstein, 2012; Weston et al., 2012; Blumstein et al., 2016).

The range of $\mathrm{AD}$ variation for the three species of Corvidae was close. The close range of $\mathrm{AD}$ variation seems natural because of the close morpho-physiological characteristics that determine their behaviour ( $\mathrm{Zo}-$ rina and Obozova, 2011; Samia et al., 2015b). The ranges of FID-F variation of rooks and hooded crows were close and almost 2.5 times wider than jackdaw range variation (Fig. 2), while in other places the FID-F variation of the three species differed little (Matzyura et al., 2015a). The values for hooded crow are comparable in Zhytomyr (0-19 m; Matzyura et al., 2015a, b) and Berlin (18-24 $\mathrm{m})$ and are higher for the closely related species Corvus brachyrhynchos in Seattle (26-31 m; Clucas and Marzluff, 2012). While FID does have a species-specific component (Blumstein et al., 2003), it also has local 
features. Only rooks show FID-F species-specificity in seven cities of Eastern Europe (Table 2).

Previous studies have shown that mean FID was strongly affected by body mass (Piratelli et al., 2015). Therefore, we could expect a close average FID of rooks and hooded crows with similar body weights. In reality, the annual average $\mathrm{AD}$ and FID of rooks was twice as large as that of hooded crows and jackdaws. It is possible that the colonial rook acted over longer distances, like waterfowl in a flock (Bregnballe et al., 2009). As for the jackdaw, its high tolerance towards people is a natural consequence of its long synanthropic history in cities in northwest Russia (Malchevsky and Pukinsky, 1983), where birds live almost exclusively in human-occupied buildings, especially in winter. The tolerance of a young urban synanthrope, the hooded crow, is still undergoing the stage of synanthropisation and urbanization (or synurbanization; Luniak, 2004), and has almost reached the tolerance of the ancient synanthrope, the jackdaw, in Cherepovets and Pskov (Table 2). We have previously shown that in the last 50 years, the intraspecific tolerance of hooded crows in Cherepovets has increased (the average nest density reaches $17-43.8$ nests per $\mathrm{km}^{2}$ in some micro-districts) and the species adapts to city life rapidly (Korotkova and Poddubnaya, 2019). Intraspecific tolerance of hooded crows to other species and humans may increase.

Available data allow ranking the species tolerance to humans (the annual average FID in descending order) in the northwest portion of Eastern Europe as Eurasian jackdaw, hooded crow, and rook (Vorontsova, 2009; present study). This order is somewhat different than what was obtained for Zhytomyr (Eurasian jackdaw, rook, hooded crow; Matzyura et al., 2015a, b), and the average annual FID values for the three species were 2-3.5 times higher in Zhytomyr than in Cherepovets. Also, the Zhytomyr average annual FID of hooded crows and jackdaws was 1.3-1.5 times higher than in Pskov (Table 2). Along a latitudinal gradient, corvid tolerance changes; FID decreases with increasing latitude.

Previously, Møller (2015) reported that in birds, FID decreases with increasing latitude. Samia et al. (2017) have shown that as latitude increases, pre-detection distances increase, and $\mathrm{AD}$ is closer to the minimal safe distance (i.e., this manifestation of phenomena can be explained by economic escape theory (Blumstein, 2003) and the reduced predation risk hypothesis (Samia et al., 2017)). Andrade and Blumstein (2019) found that statistical models containing elevation as a variable explained more of the variation in FID than did models containing latitude. The reasons for FID decreasing with increasing latitude seem to be complex. For example, in winter, up to 10,000 birds can live in Cherepovets, which is $25-30$ times higher than in summer. Citizens tolerate birds and do not persecute them, so this leads to increased tolerance of hooded crows. Birds become more tolerant towards humans during the cold period (Møller et al., 2013). FID increases where birds are treated unkindly, as in Seattle (Clucas and Marzluff, 2012). In the face of increasing general and ecological culture of people and, as a consequence, a more tolerant attitude towards wild animals, we should expect even greater tolerance of birds to humans in the future. More work is needed to understand how differences in FID are related to population trends in birds and to latitude.

\section{Conclusion}

In recent years, progress in our knowledge about predation risk assessment has been made because of a remarkable number of synthetic reviews, meta-analyses, and comparative analyses (Blumstein, 2019). Future advances require novel empirical studies, often on more than one species at a time. Our data demonstrate trends in corvid tolerance along a latitudinal gradient; FID decreases with increasing latitude. $\mathrm{AD}$ and FID of Eurasian jackdaws, hooded crows and rooks depend on the seasons. This should be taken into account in environmental protection measures.

\section{Acknowledgements}

We thank the members of the Department of Biology, Cherepovets State University, for helpful discussion, and the anonymous reviewers and Josie Boyle for their helpful comments and suggestions, which contributed to the clarity and quality of the manuscript.

\section{References}

Andrade, M. and Blumstein, D. T. 2019. Anti-predator behavior along elevational and latitudinal gradients in dark-eyed juncos. Current Zoology zoz046. https://doi. org/10.1093/cz/zoz046

Aparova, I. 2003. Nesting of Goshawk in urban forest park; pp. 13-15 in Belik, V.P. (ed). Goshawk, position in ecosystems of Russia. Penza. (In Russian)

Bateman, P.W. and Fleming, P. A. 2017. Are negative effects of tourist activities on wildlife over-reported? A review of assessment methods and empirical results. Biological Conservation 211:10-19. https://doi.org/10.1016/j.biocon.2017.05.003

Blumstein, D. T. 2003. Flight initiation distance in birds is dependent on intruder starting distance. Journal of Wildlife Management 67:852-857. https://doi. org/10.2307/3802692

Blumstein, D. T. 2019. What chasing birds can teach us about predation risk effects: past insights and future directions. Journal of Ornithology 60:587-592. https://doi. org/10.1007/s10336-019-01634-1

Blumstein, D. T., Samia, D. S. M., and Cooper, W. E. 2016. Escape behavior: dynamic decisions and a growing consensus. Current Opinion in Behavioral Sciences 12:24-29. https://doi.org/10.1016/j.cobeha.2016.08.006

Bregnballe, T., Aaen, K., and Fox A. D. 2009. Escape distances from human pedestrians by staging waterbirds in a Danish wetland. Wildfow/ Special Issue 2:115-130. 
Cherepovets. 2003. p. 516 in Encyclopedia Cities of Russia. Moscow: Big Russian Encyclopedia. (In Russian)

Clergeau, P., Savard, J. P. L., Mennechez, G., and Falardeau, G. 1998. Bird abundance and diversity along an urban-rural gradient: A comparative study between two cities on different continents. Condor 100:413-425. https://doi. $\operatorname{org} / 10.2307 / 1369707$

Clucas, B. and Marzluff, J. M. 2012. Attitudes and actions toward birds in urban areas: Human cultural differences influence bird behavior. The Auk 129(1):8-16. https://doi. org/10.1525/auk.2011.11121

Cooper, W. E. and Blumstein, D. T. 2015. Escaping from predators: an integrative view of escape decisions. Cambridge: Publisher Cambridge University Press. https:// doi.org/10.1017/CBO9781107447189

Cooper, W. E., Samia, D. S. M., and Blumstein, D. T. 2015. FEAR, Spontaneity, and Artifact in Economic Escape Theory: A Review and Prospectus; pp. 147-179 In Advances in the Study of Behavior, Naguib, M., Brockmann, H.J., Mitani, J.C., Simmons, L.W., Barrett, L., Healy, S., Slater, P.J.B. (Eds.). https://doi.org/10.1016/ bs.asb.2015.02.002

Díaz, M., Møller, A.P., Flensted-Jensen, E., Grim, T., IbáñezÁlamo, J. D., Jokimäki, J., Markó, G., and Tryjanowski, P. 2013. The geography of fear: a latitudinal gradient in anti-predator escape distances of birds across Europe. PLOS ONE 8:e64634. https://doi.org/10.1371/journal. pone.0064634

Demographia. World Urban Areas: $14^{\text {th }}$ Annual Edition: 2018 04 United Nations: 2018. 118 p. Available at: http://www. demographia.com/db-worldua.pdf.

Fernández-Juricic, E., Venier, M.P., Renison, D., and Blumstein, D. T. 2005. Sensitivity of wildlife to spatial patterns of recreationist behavior: a critical assessment of minimum approaching distances and buffer areas for grassland bird. Biological Conservation 125(2):225-235. https://doi.org/10.1016/j.biocon.2005.03.020

Fisun, K. V. 2007. Scare away distance of corvid and other birds in Orenburg; pp. 210-212, In Konstantinov, V. M. (Ed.), Crow's ecology in natural and anthropogenic landscapes. Stavropol'. (In Russian)

Jokimäki, J. and Kaisanlahti-Jokimäki, M.-L. 2012. Residential areas support overwintering possibilities of most bird species. Annales Zoologici Fennici 49:240-256. https://doi. org/10.5735/086.049.0404

Kelin, E. A. and Spiridonov, S. N. 2009. Anthropological tolerance of jackdaws under conditions of urbanization; pp. 219-220, In Ecology, evolution and taxonomy of animals. Ryazan'. (In Russian)

Korotkova, T. B. and Poddubnaya, N. Ya. 2019. Adaptation of Hooded Crow (Corvus cornix Linnaeus, 1758) to urban environment. Samarskiy Nauchniy Vesnyk 1(26):47-54. (In Russian)

Legagneux, P. and Ducatez, S. 2013. European birds adjust their flight initiation distance to road speed limits. Biology Letters 9:20130417. https://doi.org/10.1098/ rsbl.2013.0417

Livezey, K. B., Fernández-Juricic, E., and Blumstein, D. T. 2016. Database of bird flight initiation distances to assist in estimating effects from human disturbance and delineating buffer areas. Journal of Fish and Wildlife Management 7(1):181-191. https://doi.org/10.3996/082015-JFWM-078

Luniak, M. 2004. Synurbization - adaptation of animal wildlife to urban development. Proceed. 4 Int. Urban Wildlife Symp. P. 50.

Malchevsky, A. S. and Pukinsky, Yu. B. 1983. The birds of Leningrad region and adjacent areas. Vol. 2. Leningrad University Press, Leningrad. (In Russian)
Marzluff, J. M. 2017. A decadal review of urban ornithology and a prospectus for the future. Ibis 159:1-13. https:// doi.org/10.1111/ibi.12430

Matsyura, A. V., Jankowski, K., and Zimaroyeva, A. A. 2015 a. Corvidae tolerance to human disturbance in settlement landscapes of Zhytomir (Ukraine). Romanian Journal of Biology - Zoology 60(1):39-47.

Matsyura, A. V., Jankowski, K., and Zimaroyeva, A. A. 2015b. Escape behaviours of Corvidae in an urban ecosystem of Zhytomyr (Ukraine). Romanian Journal of Biology - Zoology 60(2):125-134.

Møller, A. P. 2015. Birds, pp. 88-112 In Cooper, W. E., Blumstein, D.T. (eds) Escaping from predators: an integrative view of escape decisions. Cambridge University Press, Cambridge. https://doi.org/10.1017/ CBO9781107447189

Møller, A., Grim, T., Ibáñez-Álamo, J. D., Markó, G., and Tryjanowskif, P. 2013. Change in flight initiation distance between urban and rural habitats following a cold winter. Behavioral Ecology 24(5):1211-1217. https://doi. org/10.1093/beheco/art054

Møller, A.P., Samia, D.S. M., Weston, M. A., Guay, P-」., and Blumstein, D. T. 2016. Flight-initiation distances in relation to sexual dichromatism and body size in birds from three continents. Biological Journal of the Linnean Society 117:823-831. https://doi.org/10.1111/bij.12706

Møller, A.P., Tryjanowski, P., Díaz, M., Kwieciński, Z., Indykiewicz, P., Mitrus, C., Goławski, A., and Polakowski, M. 2015. Urban habitats and feeders both contribute to flight initiation distance reduction in birds. Behavioral ecology 26(3):861-865. https://doi.org/10.1093/beheco/ arv024

Piratelli, A.J., Favoretto, G. R., and de Almeida Maximiano, M. F. 2015. Factors affecting escape distance in birds. Zoologia 32 (6):438-444. https://doi.org/10.1590/S198446702015000600002

Rezanov, A. A. 2002. Towards estimation of flight initiation distance; pp. 112-123 In Ecology of Corvidae and urban landscapes. Saransk. (In Russian)

Rezanov, A. A. 2007. Assessment of hooded crow tolerance to humans and moving vehicles; pp. 209-219 In The Hooded Crow, Corvus cornix, in Anthropogenic Landscapes of the Palearctic: Problems of Synanthropization and Urbanization, Ivanovo: X-Press. (In Russian)

Rezanov, A. A. 2018. An improved method for assessing the immediate anthropotolerance of birds. Vesnyk of MSU 2(30):23-39. (In Russian)

Ryabov, A. B. 2002. The distance of scaring colonial corvids in the anthropogenic landscape of the Ivanovo region; pp. 130-132 In Corvidae birds: ecology, behavior, folklore. Saransk. (In Russian)

Samia, D. S., Nakagawa, S., Nomura, F., Rangel, T. F., and Blumstein, D.T. 2015a. Increased tolerance to humans among disturbed wildlife. Nature communications 6:8877. https://doi.org/10.1038/ncomms9877

Samia, D. S. M., Møller, A. P., and Blumstein, D. T. 2015b. Brain size as a driver of avian escape strategy. Scientific reports 5:11913. https://doi.org/10.1038/srep11913

Samia, D. S. M., Blumstein, D. T., Díaz, M., Grim, T., IbáñezÁlamo, J. D., Jokimäki, J., Tätte, K., Markó, G., Tryjanowski, P., and Møller, A. P. 2017. Rural-urban differences in escape behavior of European birds across a latitudinal gradient. Frontiers in Ecology and Evolution 5:56. https:// doi.org/10.3389/fevo.2017.00066

Schemske, D. W., Mittelbach, G. G., Cornell, H. V., Sobel, J. M., and Roy, K. 2009. Is there a latitudinal gradient in the importance of biotic interactions? The Annual Review of Ecology, Evolution, and Systematics 40:245-269. 
Tarlow, E. M. and Blumstein, D. T. 2007. Evaluating methods to quantify anthropogenic stressors on wild animals. Applied Animal Behaviour Science 102(3-4):429-451. https:// doi.org/10.1016/j.applanim.2006.05.040

Vladyshevsky, D. V. 1975. Birds in anthropogenic landscape. Novosibirsk, Nauka. (In Russian)

Vorontsova, M. S. 2009. Population dynamics and behavior of corvids in urban landscapes of the northwestern part of Russia. Abstract of dissertation for the degree of candidate of biological sciences, Moscow. (In Russian)

Zimaroyeva, A. A., Matsyura, A. V., and Jankowski, K. 2016. Spatial patterns of habitat distribution of Corvidae (the case of urban-rural gradient). Biosystems Diversity 24(2):451-458. https://doi.org/10.15421/011661

Zorina, Z. A. and Obozova, T. A. 2011. New about brain and cognitive abilities of birds. Zoological Journal 7:784-802. (In Russian)

Ydenberg, R. C. and Dill, L. M. 1986. The economics of fleeing from predators, pp. 229-249 In Advances in the Study of Behavior, 16. Elsevier. https://doi.org/10.1016/S00653454(08)60192-8

Weston, M. A., McLeod, E. M., Blumstein, D. T., and Guay, P.J. 2012. A review of flight-initiation distances and their application to managing disturbance to Australian birds. Emu 112(4):269-286. https://doi.org/10.1071/MU12026 